\title{
A comparative study on prediction models for strength properties of LWA concrete using artificial neural network
}

\author{
Divyah Nagarajan (Main and Corresponding Author) \\ Government College of Technology, Department of Civil Engineering \\ Coimbatore (India) \\ divyah991@gmail.com \\ Thenmozhi Rajagopal \\ Government College of Technology, Department of Civil Engineering \\ Coimbatore (India) \\ drthenmozhi@gct.ac.in
}

Neelamegam Meyappan

Easwari Engineering College, Department of Civil Engineering

Chennai (India)

mnmegam@gmail.com

Manuscript Code: 1523

Date of Acceptance/Reception: 25.03.2020/21.06.2019

DOI: $10.7764 /$ RDLC.19.1.103-111

\begin{abstract}
In this study, Artificial Neural Network (ANN) model is constructed to predict the compressive strength, split tensile strength and flexural strength of lightweight aggregate concrete made of sintered fly ash aggregate. An empirical relationship between the compressive strength, split tensile strength, and flexural strength was developed and compared with that of experimental results. The models were formulated based on results obtained from laboratory experiments. The variables considered in the study are the quantity of cement and water-cement ratio. Feed forward neural network and Levenberg-Marquardt back propagation algorithm were used for training algorithm in ANN. Amongst the total data, approximately $70 \%$ of the data was considered for training, $15 \%$ for testing and the remaining $15 \%$ has been considered for validation. The developed models had more accuracy with minimum error and had a higher correlation with the correlation coefficients of 0.916 and 0.955 were obtained for the training and testing data of compressive strength prediction, 0.949 and 0.937 respectively for split tensile strength prediction, 0.926 and 0.928 respectively for prediction of flexural strength. The models were compared with the experimental data's, and the results were discussed.
\end{abstract}

Keywords: Sintered Fly ash aggregate, ANN, algorithm, variables, regression.

Introduction

The Lightweight Concrete (LWC) was pronounced to be used in the last 2000 years. The lightweight concrete is always noticed for reduced construction cost and improved functional requirements or a combination of both. The lightweight concrete has been a promising modern construction technology. Compared to normal-weight concrete, the lightweight concrete reduces the self-weight of the structure, increases the floor area, reduces the overall dimensions (Dawood \& Raml, 2008), and shows better strength and thermal insulation. Lightweight concretes can either be made of a lightweight aggregate or a foamed concrete or autoclaved aerated concrete.

Since from the 1990s, the structural lightweight aggregate concrete has been viewed differently. With advancements in technology and growing needs for the development of high-performance concrete, these lightweight aggregate concretes are modified to fit the strength and durability requirements. It is the crucial factor that is the reason for growing research in structural lightweight aggregate concrete. In this century, many efforts have been intensified for making artificial and sustainable lightweight aggregates manufactured with varying proportions of industrial byproducts. The behaviour, quality and properties of lightweight structural concrete incorporating such aggregates are already under research (Nadesan \& Dinakar, 2017). But still, there is a research gap in understanding the properties and behaviour of lightweight aggregate concrete. The cause may be due to the type of admixture added for making the lightweight aggregate and the type of experimental approach. The difference in experimental results reveals the variability in the production of LWA and variation of parameters simultaneously during experiments.

In this study, the use of artificially made lightweight aggregate is used for forming the concrete. The aggregates were produced by sintering process of fly ash that is obtained from thermal power plants. The fly ash is processed with admixtures subjected to heat treatment and finally sintered to form sintered fly ash lightweight aggregates. The 
lightweight concrete is produced from these aggregates, and the properties were studied under laboratory experiments.

The basic mechanical properties of concrete are generally obtained from the standard concrete specimen after curing of 28 days. Although much literature and international codes are available for mix designing and proportioning of concrete, the lightweight concrete has to be mix proportioned only by trial mixes (Bogas \& Gomes, 2013). The following approaches are described to concrete mix proportioning:

- Identifying a starting set of mixture proportions.

- Performing many trial batches following different mix proportions until all criteria satisfied.

By following mix design procedures for lightweight concrete, interactions among the concrete constituents cannot be accounted for, and there is no means to achieve an efficiently optimized mixture for a given criterion. The usual methods of predicting the mechanical properties are generally based upon linear and non-linear static analysis and regression models are constructed in addition to that. Furthermore, the use of sintered fly ash lightweight aggregate in concrete modifies these properties and choosing a suitable regression equation involves technique and experience and is not a simple thing.

The strength of concrete depends upon various factors. Statistical experimental design methods are an essential technique to achieve the desired properties and to optimize the mixture with desired strength. They are used widely in industries to optimize processes and products and have been applied in some research studies on improving highperformance concrete. The process had been applied in concrete mix proportioning. By using statistical methods in the trial batch process, it reduces the time consumes to optimize the required percentage of different materials used. Trial batches are then carried out, test specimens are fabricated and tested, and results are analyzed using standard statistical methods. Although the regression analysis seems to be simpler and easier, there lies the difficulty in the analysis as the number of independent variables increases the accuracy decreases. However, multiple regression analysis increases the accuracy of the model. In complex cases, to improve the accuracy of the predicted models, various optimization techniques like Artificial Neural Networks (Bingol, Tortum, \& Gul, 2013; Slonski, 2010; Ramana, Anita, Mandal, Kaliappan, Shaikh, Sivaprasad, Dayal, \& Khatak, 2009) adaptive neuro-fuzzy inference systems (Bogas \& Gomes, 2013; Madandoust, Bungey, \& Ghavidel, 2012; Tortum, Yayla, \& Gokdag, 2009), factorial design (Correia, Partala, Loch, \& Segadães, 2010), genetic-based algorithms, model tree (Deshpande, Londhe, \& Kulkarni, 2014) gene expression programming (Alkroosh, \& Sarker, 2019) and adaptive network-based fuzzy inference system (ANFIS) (Sadrmomtazi, Sobhani, \& Mirgozar, 2013) can be adopted. Therefore, for complex models, the strength can be predicted by using various mapping models in concrete rather than using regression equations. This paper intends to incorporate the fundamental aspects of Artificial Neural Network as a solution to solve complex non-linear problems in predicting the mechanical properties of concrete in terms of its strength. This methodology would be economical and more comfortable rather than to develop concrete by laboratory experiments (Yaseen, Deo, Hilal, Abd, Cornejo Bueno, Salcedo-Sanz, \& Nehdi, 2018).

The idea of the neural network has been obtained from the concept of the human brain with extensive parallel interconnections. The Artificial Neural Network (ANN) is a copy of the neural network system wherein computer is used with software and hardware components with interconnections in it. Still, it is subjected to certain limitations (Dantas, Leite, \& Nagahama, 2013). ANN adopts the input parameters and trains itself to predict linear and non-linear problems establishing a better relationship with minimal errors. ANN is a useful tool for the prediction of various aspects in the field of engineering with higher confidence ( $\mathrm{Ni} \& \mathrm{Wang}, 2000)$. ANNs are being used continuously to solve different problems in civil engineering. The use of ANN for modelling concrete compressive strength has been documented from early days of research (Ni \& Wang, 2000).

\section{Description of the Problem}

Concrete is a non-linear material; therefore, there exists a complicated relationship between the various factors influencing the properties of the mix. The sintered fly ash aggregate itself is manufactured by processing fly ash using admixtures. Therefore, the effect of non-linearity is highly pronounced in the LWC made up of sintered fly ash aggregate. The aggregate is porous with a spongy structure, and it has a $16 \%$ water absorption rate (observed from laboratory experiment). The mix design plays a predominant role in determining concrete properties. The lightweight aggregate significantly influences the properties of concrete produced (Grubl, 1979), volume fraction, particle size and shape and interfacial roughness of aggregates, cement paste, water-cement ratio and admixture volume, curing conditions, and slump (Wu, Wei, Liu, \& Xing, 2016). The failure mechanism of lightweight concrete is quite 
complicated, and it is essential to understand the influencing factor affecting the concrete strength. Although the crack pattern and failure characteristics of the lightweight concrete is evaluated through experiments (Prakash et al., 2020), the mix design can be formulated only through laboratory trials which is time-consuming and laborious. Mixture design optimization is motivated by an ever-increasing need for designers and decision-makers to proportion concrete mixtures that satisfy multiple - frequently competing - performance requirements, including cost, workability, mechanical properties, durability, and environmental sustainability.

This study aims to optimize the mixing proportion of sintered fly ash aggregate concrete using neural networks (NNs) derived from genetic algorithms (GAs) for increasing the use of sintered fly ash aggregate. Compressive strength of concrete can be predicted by using multilayer feed-forward neural networks ( $\mathrm{Ni}, \&$ Wang, 2000) and mix proportions are optimized using cellular genetic algorithms (Rajasekaran, Amalraj, \& Anandkumar, 2001) whereas neural nets are developed for applications in concrete structures (Hadi, 2000). These tools were used to predict the compressive strength, split tensile strength and flexural strength of the concrete at 28 days, and sensitivity analysis of the NN based on GA was used to find the mixing ratio of sintered fly ash aggregate concrete.

Methodology

\section{Model Construction}

The problem was defined with the factors influencing the non-linear input-output relation and the 28 days compressive, split tensile and flexural strength of concrete. The architecture of the network model in Figure 1 shows that the input layer consists of 5 nodes, a hidden layer has 11 nodes and one output layer corresponding to the strength (compressive, split and flexural). For predicting the 28-day compressive strength of Normal weight aggregate concrete, a single-layer ANN model was used ( $\mathrm{Ni}, \&$ Wang, 2000) and it revealed a good prediction accuracy whereas a model with 11 inputs, seven neurons in one hidden layer, and one output and seven inputs, five and three neurons in each hidden layer, and two outputs (Oztas et al., 2006), respectively also provided a good prediction accuracy. This means training and validation plays a major role while using the prediction tool. In the case of Lightweight aggregate concrete, ANN-based estimation of compressive strength of LWAC fabricated in the laboratory environment (Alshihri, Azmy, \& Elbisy, 2009; Tavakkol et al., 2013). In addition, the ANN model has a single hidden layer structure used for predicting the Poisson ratio (Davraz, Kilinçarslan, \& Ceylan, 2015) and compressive strength based on measured ultrasonic pulse velocity (Tenza-Abril, Villacampa, Solak, \& Brotons, 2018) These experimental results provided the feasibility of the ANN to model the non-linear relation between various parameters and concrete properties.

The nodes are fully connected with its neighbouring layers. The data are obtained from the experimental work conducted by the authors in the laboratory, and the significant factors that affect the strength of concrete are identified as Cement (C), Coarse aggregate (CA), Fine aggregate (FA), Superplasticizer (SP) and water-cement ratio(W/C). The data are divided into a learning set and testing test.

Figure1. The architecture of the network model. Source: Self-elaboration.

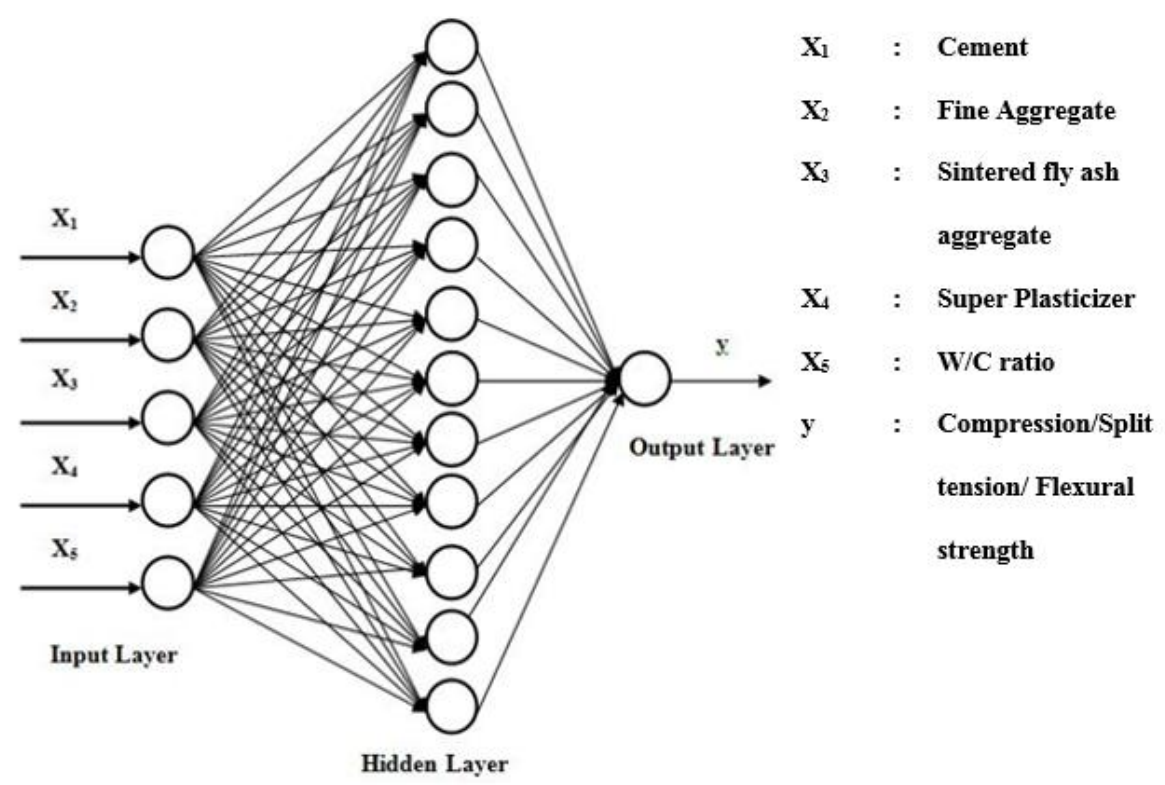


The data were collected from detailed laboratory investigations over 147 mixes to construct the learning and testing set. The cement used for the investigation is ordinary Portland cement of grade 53 . The sintered fly ash aggregates were factory-made, and it was a porous, spongy lightweight aggregate, round and with a size of $12 \mathrm{~mm}$ to $4.75 \mathrm{~mm}$. The natural, locally available river sand is used as a fine aggregate. The total volume of fine aggregate with respect to the lightweight aggregate was varied in such a way that it satisfies the mix proportion guidelines in each set. The water-cement ratio was varied as 0.4 , and 0.45 and the dosage of cement were varied from $300 \mathrm{~kg} / \mathrm{m}^{3}$ to $450 \mathrm{~kg} / \mathrm{m}^{3}$ as per IS 10262:2009 and IS 456:2000. The superplasticizers used in this experiment are polycarboxylate ether-based. $100 \mathrm{~mm} \times 100 \mathrm{~mm} \times 100 \mathrm{~mm}$ specimens were cast for compression testing, $100 \mathrm{~mm}$ diameter and $150 \mathrm{~mm}$ height cylinder was cast for split tension test, and $100 \mathrm{mmx100} \mathrm{mm \times 500} \mathrm{mm} \mathrm{prism} \mathrm{was} \mathrm{cast} \mathrm{to} \mathrm{find} \mathrm{out} \mathrm{flexural} \mathrm{strength} \mathrm{of}$ the specimens. The specimens were water cured for 28 days in a curing cabinet with relative humidity more than $95 \%$, the temperature of 27-degree Celsius was maintained.

For 147 mixes, the corresponding mechanical properties were found out at 28 days of age. For each mix, 5 influencing factors as Cement (C), Coarse aggregate (CA), Fine aggregate (FA), Superplasticizer (SP) and water-cement ratio (W/C) form an input vector are determined. The 28 days strength form the output vector. With the total data of 147 mixes, approximately $70 \%$ was considered for training, $15 \%$ for testing and $15 \%$ for validation.

On a supervised learning algorithm, the error in prediction is significantly reduced with more data vectors, and the weights are adjusted to a better level. In practical consideration, the network can yield better results with minimal error (Yoon, Kim, Lee, \& Sim, 2019). Therefore, with a large number of data available, higher is the accuracy of the results.

Results and discussion

\section{Training Phase}

The feed-forward network and backpropagation algorithm (Simsek \& Uygunoglu, 2016) for developing the neural network models has been used for the analysis. In this study, the Levenberg-Marquardt (LM) algorithm (Akyuncu, Uysal, Tanyildizi, \& Sumer, 2018) has been used to synthesize models of Artificial Neural Network. This algorithm uses layered feed- networks, in which neurons are arranged in layers, signals are sent forward, and errors are spread backwards.

Totally three individual models are developed for each noted mechanical properties. The results indicate that the proposed artificial neural network model is successful in learning the relationship between the different input and the output parameters. Three models have been generated using one hidden layer and 11 neurons in the hidden layer. Around $70 \%$ of the information was taken into account for formulation within the total data. Of the remaining $30 \%$, $15 \%$ was considered for testing, and $15 \%$ was considered for validation.

The non-linear sigmoidal function was adopted as the transfer function. The number of iterations required to converge with the neural network model is called the epoch. It is an implication of the number of times the weights have been reset to a satisfactory model with the highest possible correlation. Correlation coefficient (R) obtained for the training, testing, validation and overall data of each model. All neural network models have a correlation coefficient nearly equal to one (Azimi-Pour, Eskandari-Naddaf, \& Pakzad, 2020). It shows that the neural network models have a high degree of fitness to the actual values (Alshihri, Azmy, \& Elbisy, 2009).

The inputs used for the analysis include Cement (C), Coarse aggregate (CA), Fine aggregate (FA), Superplasticizer (SP) and water-cement ratio(W/C). Three models have been used for each property by fixing the final targets as Compressive strength, Split tensile strength and Flexural strength. Graphical representations between the predicted value and experimental values are plotted and discussed with the linearity of the models. Figure 2 denotes the learning results of compressive strength. The learning results of split tensile strength is shown in Figure 3 , and the results of flexural strength are shown in Figure 4. Feedforward neural network and backpropagation algorithm were used for training algorithm in ANN. Levenberg-Marquardt backpropagation algorithm is used. 
Figure 2. Learning results for Compressive Strength. Source: Self-elaboration.

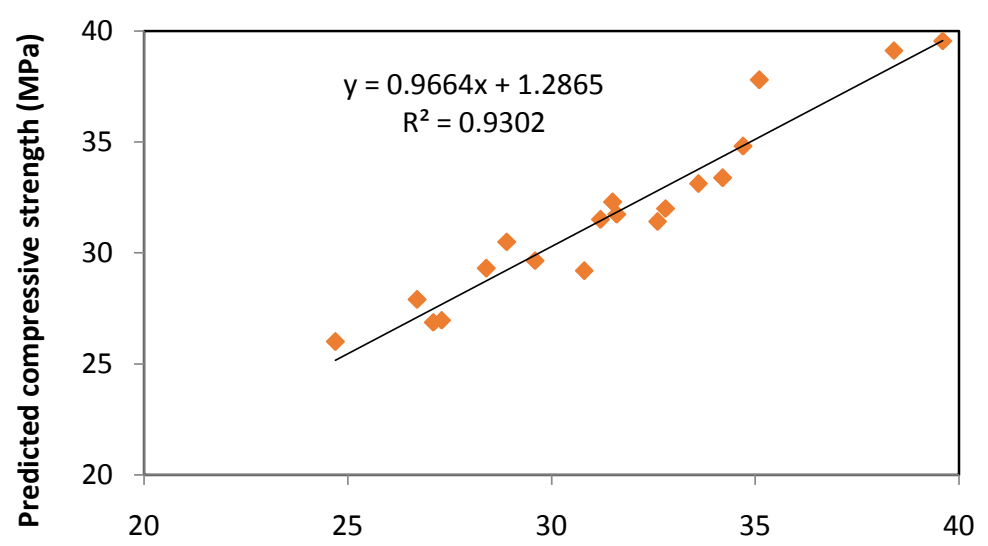

Experimental compressive strength ( $\mathrm{MPa})$

Figure 3.Learning results for Split Tensile Strength. Source: Self-elaboration.

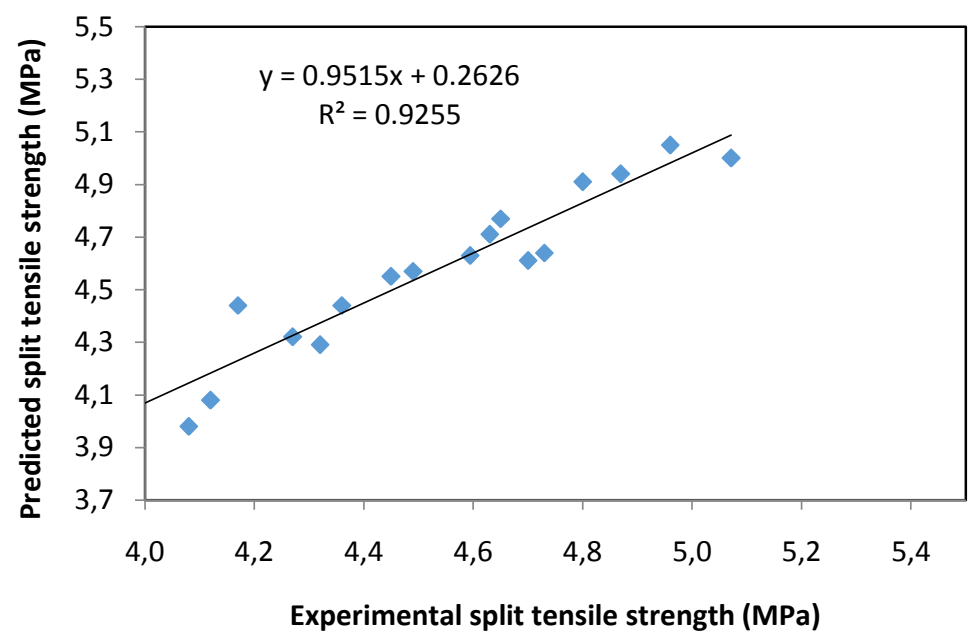

Figure 4.Learning results for Flexural Strength. Source: Self-elaboration.

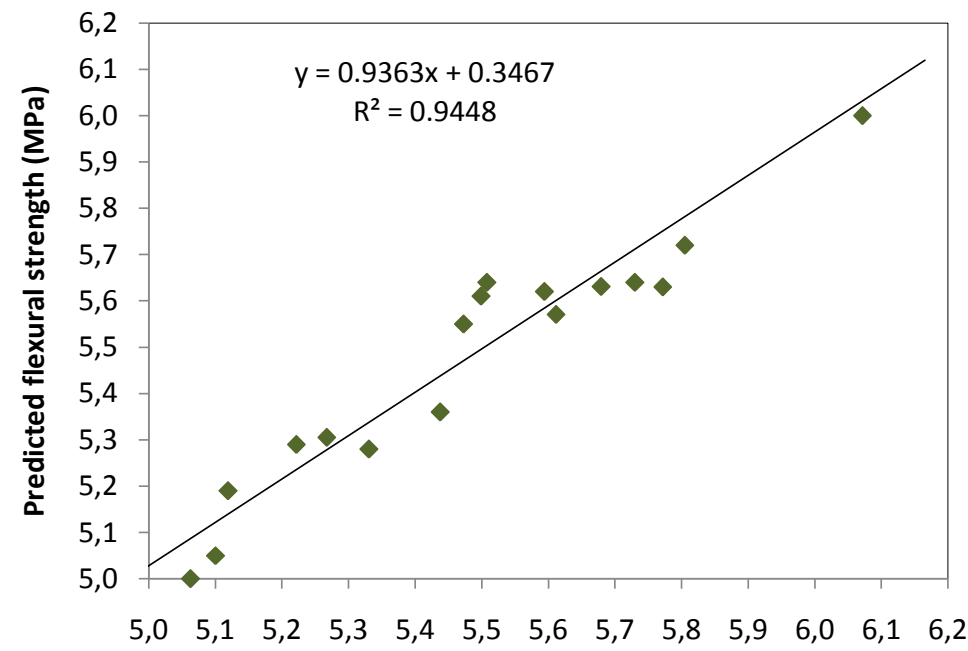

Experimental flexural strength (MPa)

In the learning phase, the network was trained in such a way that the testing set performs with good correlation between the experimental and predicted data. Nineteen testing vectors of the data were used to test the NN model. Repetitive iterations were performed to arrive at the NN model with the best results. The target output in the output neuron is correlated with the input neuron models. The results were computed in NN as a result of feed-forward calculations. 


\begin{tabular}{ccccc}
\multicolumn{5}{c}{ Table 1. Testing results for prediction of compressive strength. Source: } \\
\hline SI No. & $\begin{array}{c}\text { Target Output } \\
\text { (MPa) }\end{array}$ & $\begin{array}{c}\text { Output by NN } \\
\text { model (MPa) }\end{array}$ & $\begin{array}{c}\text { Absolute } \\
\text { Error }\end{array}$ & $\begin{array}{c}\text { Relative Error } \\
\text { (\%) }\end{array}$ \\
\hline 1 & 28.4 & 29.31 & 0.91 & 3.20 \\
2 & 30.8 & 29.20 & 1.60 & 5.19 \\
3 & 31.6 & 31.74 & 0.14 & 0.44 \\
4 & 26.7 & 27.90 & 1.20 & 4.49 \\
5 & 27.1 & 26.88 & 0.22 & 0.81 \\
6 & 27.3 & 26.97 & 0.33 & 1.21 \\
7 & 29.6 & 29.66 & 0.06 & 0.19 \\
8 & 31.2 & 31.50 & 0.30 & 0.96 \\
9 & 31.5 & 32.30 & 0.80 & 2.54 \\
10 & 32.8 & 32.00 & 0.80 & 2.44 \\
11 & 33.6 & 33.12 & 0.48 & 1.43 \\
12 & 24.7 & 26.01 & 1.31 & 5.29 \\
13 & 38.4 & 39.12 & 0.72 & 1.88 \\
14 & 34.2 & 33.38 & 0.82 & 2.40 \\
15 & 32.6 & 31.41 & 1.19 & 3.65 \\
16 & 28.9 & 30.50 & 1.60 & 5.54 \\
17 & 34.7 & 34.81 & 0.11 & 0.32 \\
18 & 35.1 & 37.80 & 2.70 & 7.69 \\
19 & 39.6 & 39.55 & 0.05 & 0.12 \\
\hline
\end{tabular}

Table 1 presents the test results of the prediction of compressive strength and Table 2 represents the test results of the prediction of Split Tensile strength. Relative errors and absolute errors were calculated from the modelling. The magnitude of the difference between the target output and the output through NN is the absolute error of the testing results. The dependent error is the absolute error divided by the target output.

\begin{tabular}{|c|c|c|c|c|}
\hline SL No. & $\begin{array}{l}\text { Target Output } \\
\text { (MPa) }\end{array}$ & $\begin{array}{c}\text { Output by NN } \\
\text { model (MPa) }\end{array}$ & $\begin{array}{c}\text { Absolute } \\
\text { Error (MPa) }\end{array}$ & $\begin{array}{c}\text { Relative Error } \\
(\%)\end{array}$ \\
\hline 1 & 4.32 & 4.29 & 0.03 & 0.69 \\
\hline 2 & 4.36 & 4.44 & 0.08 & 1.83 \\
\hline 3 & 5.07 & 5.00 & 0.07 & 1.59 \\
\hline 4 & 4.73 & 4.64 & 0.09 & 2.20 \\
\hline 5 & 4.59 & 4.63 & 0.04 & 0.87 \\
\hline 6 & 4.27 & 4.32 & 0.05 & 1.01 \\
\hline 7 & 4.65 & 4.77 & 0.12 & 3.11 \\
\hline 8 & 4.80 & 4.91 & 0.11 & 2.47 \\
\hline 9 & 4.49 & 4.57 & 0.08 & 1.70 \\
\hline 10 & 4.08 & 3.98 & 0.10 & 2.53 \\
\hline 11 & 4.12 & 4.08 & 0.04 & 0.86 \\
\hline 12 & 4.96 & 5.05 & 0.09 & 1.85 \\
\hline 13 & 4.17 & 4.44 & 0.27 & 5.32 \\
\hline 14 & 3.86 & 3.98 & 0.12 & 2.54 \\
\hline 15 & 4.45 & 4.55 & 0.10 & 2.18 \\
\hline 16 & 4.70 & 4.61 & 0.09 & 2.11 \\
\hline 17 & 3.96 & 4.04 & 0.08 & 1.72 \\
\hline 18 & 4.63 & 4.71 & 0.08 & 1.67 \\
\hline 19 & 4.87 & 4.94 & 0.07 & 1.69 \\
\hline
\end{tabular}


Table 3. Testing results for prediction of Flexural strength. Source: Self-elaboration.

\begin{tabular}{ccccc}
\hline SL No. & $\begin{array}{c}\text { Target } \\
\text { Output } \\
(\mathrm{MPa})\end{array}$ & $\begin{array}{c}\text { Output by NN } \\
\text { model (MPa) }\end{array}$ & $\begin{array}{c}\text { Absolute Error } \\
\text { (MPa) }\end{array}$ & $\begin{array}{c}\text { Relative } \\
\text { Error (\%) }\end{array}$ \\
\hline 1 & 5.22 & 5.29 & 0.07 & 1.31 \\
2 & 5.44 & 5.36 & 0.08 & 1.43 \\
3 & 5.51 & 5.64 & 0.13 & 2.40 \\
4 & 5.06 & 5.00 & 0.06 & 1.24 \\
5 & 5.10 & 5.05 & 0.05 & 0.99 \\
6 & 5.12 & 5.19 & 0.07 & 1.38 \\
7 & 5.33 & 5.28 & 0.05 & 0.95 \\
8 & 5.47 & 5.55 & 0.08 & 1.41 \\
9 & 5.50 & 5.61 & 0.11 & 2.02 \\
10 & 5.61 & 5.57 & 0.04 & 0.73 \\
11 & 5.68 & 5.63 & 0.05 & 0.85 \\
12 & 4.87 & 4.94 & 0.07 & 1.45 \\
13 & 6.07 & 6.00 & 0.07 & 1.18 \\
14 & 5.73 & 5.64 & 0.09 & 1.57 \\
15 & 5.59 & 5.62 & 0.03 & 0.46 \\
16 & 5.27 & 5.30 & 0.04 & 0.72 \\
17 & 5.77 & 5.63 & 0.14 & 2.45 \\
18 & 5.80 & 5.72 & 0.08 & 1.46 \\
19 & 6.17 & 6.23 & 0.06 & 1.04 \\
\hline
\end{tabular}

The results of the modelling were reasonably good, with minimal absolute and relative errors. It can be noted from the analysis that the flexural strength predicted through NN model from Table 3 exhibited the best-trained model when compared to that of the compressive strength model and split tensile strength model. The range of absolute and relative error in the prediction of flexural strength is found to be lesser than that of prediction of split tensile strength. The compressive strength model showed a little higher degree of error, which may be due to the nature of the artificially manufactured aggregates. Although it is a matter of the fact that the concrete made from the artificial aggregates are suspected of having some degree of non-linearity, the NN network models proved the same.

With the increasing number of iterations, at $2000^{\text {th }}$ iteration at the learning phase, the error was minimized from3.12 to 0.002 . From Figure 2,3 and 4 , it can be seen that each point in the graph denotes the standing vector. As the points gather around the diagonal line, the learning errors can be reduced. The points on the diagonal line denote that the error is zero at the learning phase.

\begin{tabular}{|c|c|c|c|c|c|c|}
\hline \multirow[b]{2}{*}{ SI.No } & \multirow{2}{*}{\multicolumn{2}{|c|}{ Model }} & \multicolumn{4}{|c|}{ Correlation coefficient } \\
\hline & & & Training & Testing & Validation & Overall \\
\hline 1 & ANN1 & $\begin{array}{l}\text { Compressive } \\
\text { Strength }\end{array}$ & 0.90458 & 0.91265 & 0.91775 & 0.91587 \\
\hline 2 & ANN2 & & 0.93217 & 0.95341 & 0.9495 & 0.95526 \\
\hline 3 & ANN1 & $\begin{array}{l}\text { Split Tensile } \\
\text { strength }\end{array}$ & 0.91423 & 0.96752 & 0.94994 & 0.94919 \\
\hline 4 & ANN2 & & 0.92366 & 0.93992 & 0.93816 & 0.93658 \\
\hline 5 & ANN1 & $\begin{array}{l}\text { Flexural } \\
\text { Strength }\end{array}$ & 0.91902 & 0.92178 & 0.92611 & 0.92551 \\
\hline 6 & ANN2 & & 0.9428 & 0.92997 & 0.929999 & 0.92812 \\
\hline
\end{tabular}


The correlation coefficients were arrived for the models and are shown in Table 4. The NN models had correlation coefficients almost equal to unity. It conforms to the fitness of the experimental values with the predicted values. Regarding the absolute and relative error values, the flexural strength of model ANN2 had higher correlation factor of 0.95526 when compared with the overall data. The least correlation factor reported was 0.91587 for the model ANN1 concerning the split tensile strength - the material non-linearity accounts to such difference in prediction.

\section{Consistency between NN modelling and Experiments}

The NN is trained in such a way that the models can be used to find out the factors affecting the strength parameters of the LWA concrete. With the lack of codal provisions on the strength properties of lightweight aggregate concrete or only lightweight concrete, the mix proportioning procedures often involve many laboratory trials. From the conclusions drawn from the experimental results and analysis results of NN models, the functional relationship between the strength properties conforms to the guidelines of mix proportioning as per Indian standard codal provisions as per IS 10262:2009. To some extent, the models formulated through NN was found to be reasonably good.

\section{Conclusions}

The Artificial Neural Network model can be used as a better guide to predicting the strength properties of concrete by considering the influencing factors that modify the properties of concrete. This method can be highly adopted by the ready-mix plants for mixture designing and batching. The degree of accuracy is found to be high, with an increasing number of iterations. The rules of mix proportioning can be followed without affecting the performance of concrete for its strength. For conditions requiring a high degree of accuracy and for solving complex problems, the ANN method can be the best applicable method when compared to the regression analysis. Regression is a method dealing with linear dependencies; neural networks can deal with non-linearities. So if the data have some non-linear dependencies, neural networks perform better than regression. Moreover, the time required for calculations is faster in NN. The regression analysis can be only applied to simple mix calculations. The current procedures of mix design are valid only for a limited range of compositions concerning a particular concrete type that has been subjected to prior experimental evaluation. The sintered fly ash aggregate is artificially made, and the strength of concrete made by using such aggregate cannot be the same in all cases owing to the composition, gradation and other factors influencing the manufacturing of aggregates itself. Furthermore, various other factors affect the concrete strength regardless of the aggregates. The behaviour of lightweight aggregate concrete can be predicted only through continuous laboratory experiments which are time-consuming and needs more workforce. This issue can be significantly solved by using these prediction methods.

References

Alkroosh, I.S., \& Sarker, P.K. (2019). Prediction of the compressive strength of fly ash geopolymer concrete using gene expression programming. Computers and Concrete, 24(4), 295-302.

Alshihri, M.M., Azmy, A.M., \& Elbisy, M.S., (2009). Neural networks for predicting compressive strength of structural light weight concrete. Construction and Building Materials, 23, 2214-2219.

Azimi-Pour, M., Eskandari-Naddaf, H., \& Pakzad, A. (2020). Linear and non-linear SVM prediction for fresh properties and compressive strength of high volume fly ash self-compacting concrete. Construction and Building Materials, 230, 117021.

Bingol, A.F., Tortum, A. \& Gul, R. (2013). Neural networks analysis of compressive strength of lightweight concrete after high temperatures. Materials and Design, 52, 258-264.

Bogas J.A. \& Gomes A. (2013).A simple mix design method for structural lightweight aggregate concrete. Materials and Structures, RILEM 2013.

Correia, S.L. Partala, T., Loch, F.C. \& Segadães, A.M. (2010). Factorial design used to model the compressive strength of mortars containing recycled rubber. Composite Structures, 92,2047-2051,

Dantas, A.T.A., Leite, M.B., \& Nagahama, K. de J. (2013). Prediction of compressive strength of concrete containing construction and demolition waste using artificial neural networks. Construction and Building Materials, 38, 717-722.

Davraz, M., Kilinçarslan Ş., \& Ceylan H. (2015). Predicting the Poisson Ratio of Lightweight Concretes using Artificial Neural Network. ACTA PHYSICA POLONICA A, 128, B-184-B-187.

Dawood E. \& Raml M. (2008). Rational Mix Design of Lightweight Concrete for Optimum Strength. 2nd International Conference on Built Environment in Developing Countries (ICBEDC 2008). School of Housing Building and Planning, Universiti Sains Malaysia. 15th June 2008. 
Deshpande, N., Londhe, S., \& Kulkarni, S. (2014). Modeling compressive strength of recycled aggregate concrete by artificial neural network, model tree and non - linear regression. International Journal of Sustainable Built Environment, 3, 187-198.

Grubl, P. (1979). Mix design of lightweight aggregate concrete for structural purposes. International Journal of Lightweight Concrete, 1(2), 63- 69.

Hadi, N. (2000).Neural network applications in Concrete Structures. Computers \& Structures, 81, 373-38.

Madandoust, R., Bungey, J. \& Ghavidel, R. (2012). Prediction of the concrete compressive strength by means of core testing using GMDH-type neural network and ANFIS models. Computational Materials Science. 51, 261-272.

Nadesan, M.S., \& Dinakar, P. (2017). Structural concrete using sintered fly ash lightweight aggregate: A review. Construction and Building Materials, $154,928-944$.

Ni, H.-G. \& Wang, J.-Z. (2000). Prediction of compressive strength of concrete by neural networks. Cement and Concrete Research, 30, $1245-1250$.

Oztas, A., Pala, M., Özbay, E., Kanca, E., Caglar, N., \& Bhatti, M.A. (2006). Predicting the compressive strength and slump of high strength concrete using neural network. Construction and Building Materials, 209, 69-75.

Prakash, R., Thenmozhi, R., Raman S.N., \& Subramanian, C. (2020). Fibre reinforced concrete containing waste coconut shell aggregate, fly ash and polypropylene fibre. Revista Facultad de Ingeniería, 94, 33-42. 10.17533/10.17533.

Ramana, K.V.S., Anita T., Mandal, S., Kaliappan, S., Shaikh, H., Sivaprasad, P.V., Dayal, R.K., \& Khatak, H.S. (2009). Effect of different environmental parameters on pitting behaviours of AISI type $316 \mathrm{~L}$ stainless steel: experimental studies and neural network modelling. Materials and Design., $30,3770-3775$.

Rajasekaran, S., Amalraj, R. \& Anandkumar, S. (2001). Optimization of mix proportions for high Performance Concrete using cellular genetic algorithms. Proceedings of National Seminar on Concrete Technology for 21 Century. Annamalai Nagar. February 2001.

Sadrmomtazi, A. Sobhani, J. \& Mirgozar, M.A. (2013). Modeling compressive strength of EPS lightweight concrete using regression, neuralnetwork and ANFIS. Construction and Building Materials, 42, 205-216.

Simsek B., \& Uygunoglu, T. (2016). A Neural Network Model for Ultrasonic Pulse Velocity and the Modulus of Elasticity of Polymer Concrete. International Journal of Advances in Chemical Engg, \& Biological Sciences (IJACEBS), 3(1).

Slonski M. (2010). A comparison of model selection methods for compressive strength prediction of high - performance concrete using neural networks. Computers and Structures, 88, 1248-1253.

Tavakkol, S., Alapour, F., Kazemian, A., Hasaninejad, A., Ghanbari, A., \& Ramezanianpour, A. (2013). Prediction of lightweight concrete strength by categorized regression, MLR and ANN. Computers and Concrete, 12, 151-167.

Tenza -Abril, A., Villacampa, Y., Solak, A., \& Brotons, F. (2018). Prediction and sensitivity analysis of compressive strength in segregated lightweight concrete based on artificial neural network using ultrasonic pulse velocity. Construction and Building Materials, 189,1173-1183.

Tortum, A., Yayla, N., \& Gokdag, M. (2009). The modeling of mode choices on intercity freight transportation with the artificial neural networks and adaptive neuro-fuzzy inference system. Expert Systems with Applications, 36(2), 6199-6217.

Akyuncu, V., Uysal, M., Tanyildizi, H., \& Sumer, M. (2018). Modeling the weight and length changes of the concrete exposed to sulfate using artificial neural network. Revista de la Construcción, 17(3), 337-353.

Wu, T., Wei, H., Liu, X., \& Xing, G. (2016). Factors influencing the mechanical properties of lightweight aggregate concrete. Indian Journal of Engineering and Material sciences, 23,301-311.

Yaseen, Z.M., Deo, R.C., Hilal, A., Abd M.A., Cornejo Bueno, L., Salcedo-Sanz, S., \& Nehdi, M.L. (2018). Predicting compressive strength of lightweight foamed concrete using extreme learning machine model. Advances in Engineering Software, 115, 112-125.

Yoon, J.Y., Kim, H., Lee, Y.-J., \& Sim, S.-H. (2019). Prediction Model for Mechanical Properties of Lightweight Aggregate Concrete Using Artificial Neural Network. Materials (Basel), 12(17), E2678. doi: 10.3390/ma12172678. 